Article

\title{
Cucurbit[8]uril-Based Potentiometric Sensor Coupled to HPLC for Determination of Tetracycline Residues in Milk Samples
}

\author{
Renato L. Gil (1), Célia M. P. G. Amorim *®), Maria da Conceição B. S. M. Montenegro (1) and Alberto N. Araújo \\ LAQV-REQUIMTE, Department of Chemical Sciences, Faculty of Pharmacy, University of Porto, \\ R. Jorge Viterbo Ferreira, 228, 4050-313 Porto, Portugal; renatogil19@gmail.com (R.L.G.); \\ mcbranco@ff.up.pt (M.d.C.B.S.M.M.); anaraujo@ff.up.pt (A.N.A.) \\ * Correspondence: camorim@ff.up.pt
}

check for updates

Citation: Gil, R.L.; Amorim, C.M.P.G.; Montenegro, M.d.C.B.S.M.; Araújo, A.N. Cucurbit[8]uril-Based Potentiometric Sensor Coupled to HPLC for Determination of

Tetracycline Residues in Milk Samples. Chemosensors 2022, 10, 98. https://doi.org/10.3390/

chemosensors10030098

Academic Editor: Boris Lakard

Received: 19 January 2022

Accepted: 1 March 2022

Published: 3 March 2022

Publisher's Note: MDPI stays neutral with regard to jurisdictional claims in published maps and institutional affiliations.

Copyright: (C) 2022 by the authors. Licensee MDPI, Basel, Switzerland. This article is an open access article distributed under the terms and conditions of the Creative Commons Attribution (CC BY) license (https:// creativecommons.org/licenses/by/ $4.0 /)$.

\begin{abstract}
The determination of chlortetracycline, doxycycline, oxytetracycline, and tetracycline in milk samples by HPLC coupled to a cucurbit[8]uril-based potentiometric sensor is herein presented. The new tetracycline-selective electrode is based on a polymeric membrane incorporating cucurbit[8]uril as a macrocyclic host, potassium tetrakis(p-chlorophenyl) borate as an ionic additive, 2-fluorophenyl 2-nitrophenyl ether as a plasticizer, and multi-walled carbon nanotubes as nanostructured materials. A microfluidic wall-jet flow-cell is implemented as a potentiometric detector after chromatographic separation by a C8 column using a gradient mobile phase of sulphuric acid and acetonitrile. The proposed methodology was validated following International Council for Harmonisation of Technical Requirements for Pharmaceuticals for Human Use (ICH) and European Union (EU) guidelines. Linear regression models provided $R^{2}$ in the range from $0.9973 \pm 0.0026$ to $0.9987 \pm 0.0012$ for all tetracycline antibiotics. The limits of detection and quantification ranged from 13.3 to $46.0 \mu \mathrm{g} \mathrm{L}^{-1}$ and 44.4 to $92.1 \mu \mathrm{g} \mathrm{L}^{-1}$, respectively. Precision intra-day, inter-day, and inter-electrode showed relative standard deviation values lower than $12.5 \%, 13.5 \%$, and $12.9 \%$, respectively. Accuracy was assessed by analysis of spiked milk samples around the maximum residue limit, yielding recovery values in the range from 81.3 to $108.5 \%$. The simple, sensitive, cost-effective, and reliable HPLC-ion-selective electrode method justifies its use as a competitive alternative for the analysis of tetracycline residues in the food quality control sector.
\end{abstract}

Keywords: tetracycline antibiotics; milk; HPLC; potentiometry; ion-selective electrodes; cucurbit[8]uril

\section{Introduction}

Tetracycline antibiotics (TCs) are broad-spectrum pharmaceutical drugs that exhibit activity against a wide range of microorganisms [1]. The most used compounds within this antibiotic group are chlortetracycline, doxycycline, oxytetracycline, and tetracycline. The low toxicity profile and low cost enhance their extensive use as veterinary drugs for the prevention and treatment of several microbial diseases [2] as well as growth promoters in intensive animal farming [3]. This widespread use of TCs may cause the presence of residues in foods of animal origin, whose intake result in harmful effects on human health such as allergic reactions, gastrointestinal disturbance, liver damage, poor fetal development, and pigmentation of teeth [4,5]. Moreover, the consumption of low-level doses for long periods induces the selective predominance of drug-resistant microorganisms with time, which puts public health in jeopardy [6].

To ensure food safety and reduce the exposure of people to veterinary drugs, regulatory authorities have set maximum residue limits (MRLs) allowed in foods for human consumption. The MRLs for TCs residues, according to the US Food and Drug Administration (FDA), are $2 \mathrm{mg} \mathrm{kg}^{-1}$ in muscle, $6 \mathrm{mg} \mathrm{kg}^{-1}$ in the liver, and $0.3 \mathrm{mg} \mathrm{kg}^{-1}$ in milk [7], whereas the Codex Alimentarius Commission of the FAO/WHO has adopted MRLs of 
$0.2 \mathrm{mg} \mathrm{kg}^{-1}$ in muscle, $0.6 \mathrm{mg} \mathrm{kg}^{-1}$ in the liver, and $0.1 \mathrm{mg} \mathrm{L}^{-1}$ in milk [8]. These low MRL values demand the use of analytical methods with suitable sensitivity and detectability to determine these residues in foodstuff.

Different analytical methodologies for the determination of TCs in milk samples have been reported in the literature, with an emphasis on HPLC coupled to photodiode array [9]. The complexity of the chromatograms nonetheless requires a positive correspondence of compounds to the peaks by comparing the sample and reference spectra. Fluorimetric detection improves both selectivity and sensitivity but requires post-column derivatization [10]. On the other hand, LC-MS/MS methods with the best figures of merit have been developed for the determination of TCs residues [11-13]. However, the high cost and the requirement of skilled technicians are not easy to circumvent, which make this method unaffordable for routine analysis. Although effective methods are already implemented, more simple, rapid, inexpensive, and reliable analytical methodologies are needed to fulfill the requirements of governmental agencies and consumer organizations [9].

Of particular interest is the potentiometric technique based on ion-selective electrodes (ISEs) due to their versatility of use, simplicity of instrumentation, cost-effectiveness, and miniaturization ability [14,15]. The coupling of potentiometric detection with liquid chromatography was considered decades ago by using metallic copper electrodes [16-18] for the determination of inorganic ions in ion chromatography systems. Later on, Luc Nagels and his group extended the applications to organic ionic substances, including organic acids [19], basic drugs [20,21], and alkaloids [22], resorting to polymeric membrane electrodes based on a conductive support. Despite their powerful features, potentiometric sensors are still not viewed as routine detectors in HPLC and thus researchers should put more effort into demonstrating their competitiveness with other detectors.

Several ISEs using different types of recognition elements have been described in the literature to accomplish the determination of TCs. Electroactive ion-pair complexes were initially proposed for the determination of chlortetracycline [23] and tetracycline [24], though the poor limits of detection (LOD) strongly limited their application. Alternatively, molecularly imprinted polymers (MIPs) for the determination of oxytetracycline [25] and tetracycline [26,27] were also considered. Nevertheless, the poor LOD [25,26], the long response time $(\approx 200 \mathrm{~s})$, and the inner filling solution configuration hindered its use in microfluidic platforms [27]. The use of macrocyclic receptors as recognition elements to form inclusion complexes by a host-guest mechanism [28,29], such as $\alpha$-cyclodextrin [30] and $\beta$-cyclodextrin [31], has been referred as a convenient approach in the development of tetracycline-selective electrodes (TC-SE) with improved sensitivity and detection limits. Nevertheless, none of these potentiometric sensors were used together with chromatographic separation, and thus the simultaneous detection of different TCs with suitable LOD was still a real limitation.

Recently, the cucurbit[n]urils (CB[n]s) family has attracted significant attention due to their interesting molecular recognition properties [32]. $\mathrm{CB}[\mathrm{n}] \mathrm{s}$ are barrel-shaped macrocyclic hosts with a hydrophobic inner cavity accessed via two polar carbonyl-rimmed openings [33]. While the cavity provides a hydrophobic void to host neutral hydrophobic molecules, the carbonyl rims represent docking sites for positively charged groups and stabilize the host-guest complex through ion-dipole and hydrogen-bonding interactions [34]. Different $\mathrm{CB}[\mathrm{n}] \mathrm{s} /$ organic compound complexes have been described in the literature by using spectroscopic [35-37] and electroanalytical techniques [38-40]. Particularly in potentiometric detection, $\mathrm{CB}[6]$ was considered for the development of etilefrine [41] and atropine [42] selective electrodes for pharmaceutical control as well as biogenic amine determination in different food samples [43,44]. However, based on the authors' knowledge, to date, no TC-selective electrode has been reported based on $\mathrm{CB}[\mathrm{n}]$ as a recognition element to determine the presence of TCs in food matrices.

Therefore, this work intends to develop a simple, cost-effective, and reliable method for the determination of TCs by HPLC coupled with potentiometric detection. To achieve this goal, a novel TC-selective electrode based on $\mathrm{CB}[8]$ as an ionophore was developed and 
integrated into a microfluidic wall-jet flow-cell, which was used as a detector in a reversedphase HPLC system. The final methodology was validated following the international guidelines and was applied to the analysis of milk samples.

\section{Experimental Section}

\subsection{Chemicals and Solutions}

All chemicals were of analytical reagent grade. Chlortetracycline hydrochloride (CTC, $\geq 91.0 \%$, ref. C4881), doxycycline hyclate (DXC, $\geq 93.5 \%$, ref. D9891), oxytetracycline hydrochloride (OTC, >96.5\%, ref. O5875), tetracycline hydrochloride (TTC, 95.0\%, ref. T3383), oxalic acid dihydrate (ref. 1.00495), citric acid (ref. 251275), sodium phosphate dibasic dihydrate (ref. 71662), and ethylenediaminetetraacetic acid disodium salt dihydrate (EDTA, ref. E5134) were purchased from Sigma-Aldrich (Algés, Portugal). Sulphuric acid was from PanReac AppliChem (96\%, $\mathrm{H}_{2} \mathrm{SO}_{4}$, ref. 131058) while acetonitrile (ACN, ref. 1.00029.2500P) and methanol (MetOH, ref. 1.06035.2500P) of LiChrosolv hyper grade were acquired from VWR (Amadora, Portugal). Ultra-pure water with conductivity $<0.055 \mu \mathrm{S} \mathrm{cm}^{-1}$ was produced in our laboratory (Heal force, Easy model, Shanghai, China) and used whenever needed.

The stock standard solutions of TCs were prepared in an aqueous oxalic acid solution $(0.05 \mathrm{M})$ at the concentration level of $0.01 \mathrm{M}$ and stored in the freezer at $-20{ }^{\circ} \mathrm{C}$ before use. The working standard solutions were prepared daily by the subsequent dilution of the stock solution. The EDTA/Mcllvaine Buffer was prepared according to the literature [45] by mixing a $0.1 \mathrm{M}$ aqueous solution of citric acid with a $0.1 \mathrm{M}$ aqueous solution of anhydrous dibasic sodium phosphate $(100: 62.5, v / v)$. Then, the corresponding mass of disodium EDTA for a final concentration of $0.1 \mathrm{M}$ was added, and the $\mathrm{pH}$ was adjusted to 4.1 with a $5 \mathrm{M}$ sodium hydroxide solution (measured with a sensION pH meter, Hach, Portugal).

For the electrode conductive support preparation, graphite powder $(<50 \mu \mathrm{m}$, ref. 1.04206) and Araldite M (ref. 10951) were purchased from Sigma-Aldrich (Algés, Portugal), whereas the hardener Ren HY 5162 (ref. 068620205) was from Huntsman (Barcelona, Spain). For the sensing membranes preparation, high molecular weight polyvinyl chloride (PVC, ref. 81392), cucurbit[8] uril hydrate (CB[8], ref. 545228), potassium tetrakis(pchlorophenyl)borate (TCPB, ref. 60591), 2-fluorophenyl 2-nitrophenyl ether (FNDPE, ref. 47390), multi-walled carbon nanotubes (MWCNTs, 110-170 nm $\times 5-9 \mu \mathrm{m}$, ref. 659258), and tetrahydrofuran (THF, ref. 186562) were obtained from Sigma-Aldrich (Algés, Portugal).

\subsection{Sample Preparation}

Milk samples were purchased from a local supermarket (Porto, Portugal), which included UHT skimmed milk, UHT semi-skimmed milk, and fresh semi-skimmed milk, and were stored at $4{ }^{\circ} \mathrm{C}$ (for no more than one week). Firstly, $1.0 \mathrm{~mL}$ of each milk sample was mixed with $5.0 \mathrm{~mL}$ of EDTA/Mcllvaine Buffer in a $15 \mathrm{~mL}$ centrifuge tube. The solutions were agitated for $1 \mathrm{~min}$ using a vortex, followed by centrifugation at $4750 \mathrm{rpm}$ for $15 \mathrm{~min}$ at $4{ }^{\circ} \mathrm{C}$. Any floating lipid layer and precipitate were disposed of, being the remaining supernatant cleaned-up with solid-phase extraction (SPE) cartridges OASIS PRIME hydrophobic-lipophilic-balanced (HLB) from Waters (3 cc, 60 mg, ref. 186008056) assembled in a Visiprep ${ }^{\text {TM }}$ SPE Vacuum Manifold (ref. 57030-U, Supelco). The supernatant was loaded into the SPE cartridge at a flow rate of $1.0 \mathrm{~mL} \mathrm{~min}^{-1}$. After the sample was percolated, the cartridges were washed with $2.0 \mathrm{~mL}$ of ultra-pure water and dried for $1 \mathrm{~min}$ drawing a full vacuum. The target analytes were eluted twice by $1.0 \mathrm{~mL}$ of HPLC grade methanol at the same flow rate. The extract was dried under a gentle nitrogen stream and was finally reconstituted in $1.0 \mathrm{~mL}$ of aqueous oxalic acid at $0.05 \mathrm{M}$. All solutions were filtered through $0.22 \mu \mathrm{m}$ Nylon syringe filters (FilterLab, ref. JNY022013N) before injection in the chromatographic system. 


\subsection{Apparatus}

The HPLC-ISE analysis was performed on a Waters 600E Multisolvent Delivery System (Waters, Milford, MA, USA) equipped with a Waters 600 controller, a Waters 600E pump, a Waters 2487 Dual Absorbance Detector, and a Rheodyne 7725i six-port external manual injector (IDEX Health \& Science, LLC, Middleboro, MA, USA). Millennium 32 Chromatography Manager Software (Waters, Milford, MA, USA) was used to control the HPLC components and data processing in the UV detector.

Handmade miniaturized indicator electrodes and a commercial miniaturized reference electrode filled with a 3.0 M KCl (model 6.0727.0 0 0, Metrohm, Herisau, Switzerland) were used for the potentiometric measurements, which were carried out using a 6-Channel Precision Electrochemistry EMF Interface (LawsonLabs, Inc., Malvern, PA, USA). A doublejunction $\mathrm{Ag} / \mathrm{AgCl}$ reference electrode (Orion 90-02-00, Thermo Scientific, Waltham, MA, USA) with its external compartment filled with a $0.01 \mathrm{M} \mathrm{KCl}$ solution was used in the experiments in batch mode. The potentiometric signals vs. time data were recorded by the graphics software from LawsonLabs, Inc., Malvern, PA, USA.

\subsection{Chromatographic Conditions}

A Luna C8(2) column $(150 \mathrm{~mm} \times 4.6 \mathrm{~mm}$ I.D., $5 \mu \mathrm{m}$ from Phenomenex, Torrance, CA, USA) was used at controlled room temperature $\left( \pm 2{ }^{\circ} \mathrm{C}\right)$ to perform the separation using a mobile phase composed of solvent $\mathrm{A}\left(0.005 \mathrm{M} \mathrm{H}_{2} \mathrm{SO}_{4}\right.$ :ACN, 90:10, $\left.v / v\right)$ and solvent $\mathrm{B}$ $\left(0.005 \mathrm{M} \mathrm{H}_{2} \mathrm{SO}_{4}: \mathrm{ACN}, 80: 20, v / v\right)$. A gradient elution was used following the program: $0 \%$ B from 0 to $13.00 \mathrm{~min}$; 0-100\% B from 13.00 to $13.01 \mathrm{~min} ; 100 \%$ B from 13.01 to $24.00 \mathrm{~min}$; $100-0 \%$ B from 24.00 to $24.01 \mathrm{~min}$. The injection volume and the flow rate were optimized to be $100 \mu \mathrm{L}$ and $1.30 \mathrm{~mL} \mathrm{~min}^{-1}$, respectively.

\subsection{Detection Cell}

The column outlet was connected in-line to the Waters Absorbance Detector at a wavelength of $355 \mathrm{~nm}$, according to the literature [45,46], which was used to validate the potentiometric measurements. The microfluidic potentiometric wall-jet flow-cell (Figure 1) holding both the miniaturized TC-selective electrode and the reference electrode was in-line connected after the UV detector using PEEK tubing ( $\times$ O.D. $\times$ I.D. $=300 \mathrm{~mm} \times 1 / 16 \mathrm{in} . \times 0.25 \mathrm{~mm}$ ). The flow-cell consisted of an acrylic block (length $-40 \mathrm{~mm}$, width $-22 \mathrm{~mm}$, and height$22 \mathrm{~mm}$ ) incorporating four single holes: two for the inlet and outlet of the mobile phase, one enabling to screw the reference electrode, and the last for coupling the miniaturized TC-selective electrode. The internal channel was drilled with an internal diameter of $0.8 \mathrm{~mm}$. For the inlet and outlet, a blue ferrule and male red nut (1/16, IDEX Health \& Science) were used to connect the PEEK tubing.

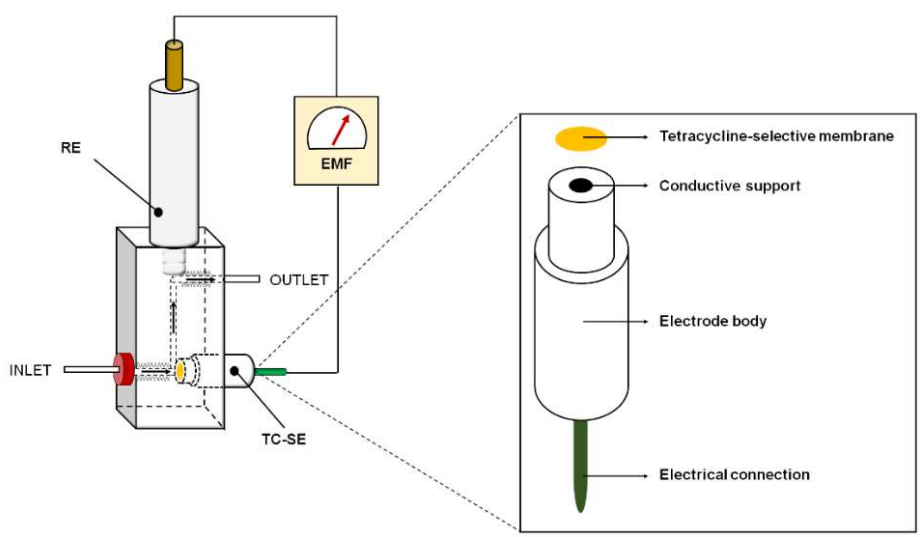

Figure 1. Illustration of the microfluidic wall-jet potentiometric cell used for the determination of tetracycline antibiotics. TC-SE-Tetracycline-selective electrode; RE-Reference electrode. Inset: Miniaturized TC-SE based on graphite conductive substrate prepared by the drop-casting of a tetracycline-selective membrane. 


\subsection{Preparation of the TC-Selective Electrodes}

Handmade TC-selective electrodes of solid contact were fabricated following a procedure described elsewhere [44,47]. Briefly, a non-conductive epoxy resin was prepared by mixing Araldite-M and hardener HY (1:0.4 w/w), which was blended with graphite powder to obtain a composite with appropriate homogeneity and consistency. The final proportion was 1:1.85 $w / w$ of epoxy resin and graphite, respectively. A portion of the conductive composite was introduced in one end of a Perspex tube (6.0 mm I.D. $\times 10.0 \mathrm{~mm}$ O.D. $\times 150.0 \mathrm{~mm}$ length) and a polytetrafluoroethylene rod (1.6 mm I.D. $\times 4.0 \mathrm{~mm}$ O.D. $\times 15.0 \mathrm{~mm}$ length) for the fabrication of conventionally shaped and miniaturized electrodes, respectively. An electrically shielded cable with the copper wire exposed was inserted from the opposite endings to establish the electrical contact. The electrodes were left to dry over $24 \mathrm{~h}$ at room temperature and, finally, the surface was polished with sandpaper of different grit sizes until a specular gloss was obtained.

Ion-selective membranes (ISMs) were prepared by mixing accurately weighed amounts of the polymer (PVC), plasticizer (FNDPE), ionophore (CB[8]), ionic additive (TCPB), and nanostructured materials (MWCNTs) in glass vials to obtain the compositions shown in Table 1. A total of $300 \mathrm{mg}$ of the mixture was dissolved in $3.0 \mathrm{~mL}$ of THF and shaken in a vortex before use. The conductive electrode surface was modified by dropping the corresponding ISMs until covering all the support contact areas $(\approx 100 \mu \mathrm{L})$. The THF was left to evaporate for $30 \mathrm{~min}$ before the next deposition. The procedure was repeated a further five times and, finally, the electrodes were left to dry overnight before conditioning in an aqueous $0.05 \mathrm{M}$ solution of oxalic acid. For miniaturized electrodes, $4 \times 5 \mu \mathrm{L}$ of the corresponding ISM was drop-coating onto the conductive support with an automatic pipette. Each layer was allowed to dry for $20 \mathrm{~min}$ before the next addition. Finally, the electrodes were conditioned overnight $(\sim 12 \mathrm{~h})$ in an aqueous $0.005 \mathrm{M}$ solution of sulphuric acid. When not in use, each electrode was kept immersed in the corresponding conditioning solution.

Table 1. Ion-selective membranes (ISMs) composition.

\begin{tabular}{cccccc}
\hline & \multicolumn{5}{c}{ Components in the ISM (wt\%) } \\
\cline { 2 - 6 } ISM & PVC & FNDPE & CB[8] & TCPB & MWCNTs \\
\hline A & 31.00 & 68.97 & - & 0.03 & - \\
B & 31.00 & 68.07 & 0.90 & 0.03 & - \\
C & 31.00 & 67.07 & 0.90 & 0.03 & 1.00 \\
D & 31.00 & 66.07 & 0.90 & 0.03 & 2.00 \\
\hline
\end{tabular}

PVC-polyvinyl chloride; FNDPE-2-fluorophenyl 2-nitrophenyl ether; $\mathrm{CB}[8]$ —cucurbit[8]uril hydrate; TCPBpotassium tetrakis(p-chlorophenyl)borate; MWCNTs-multi-walled carbon nanotubes.

\section{Results and Discussion}

\subsection{Evaluation of the Conventionally Shaped TC-Selective Electrodes}

The potentiometric response of conventionally shaped electrodes prepared with different membranes (without CB[8]-ISM A and with CB[8]_ISM B) was firstly evaluated towards four different TCs in batch conditions. The background solution of $0.05 \mathrm{M}$ oxalic acid solution at a pH of 2.0 allowed for the total ionization of TCs and the ionic strength adjustment. Figure S1 shows the typical time trace of the EMF values of both electrodes for the stepwise addition of various concentrations of each of the TCs. The EMF values observed at the steady-state were plotted against the corresponding logarithmic TCs' concentration, showing a Nerstian behavior for all target compounds (Figure S2). The general calibration parameters (Table 2), namely slope, linear response range, and LOD, showed high similarity between the sensing membrane without (ISM A) and with the addition of ionophore (ISM B). Noteworthy, the intra- and inter-electrode potentiometric responses were highly reproducible ( $\mathrm{n}=3$ for electrodes and successive calibrations), since the given relative standard deviation (RSD) of the obtained slopes was better than $3.0 \%$ and $4.1 \%$ for ISM A and ISM B, respectively. 
Table 2. Calibration parameters of the conventionally shaped electrodes prepared without (ISM A) and with ionophore (ISM B) in batch mode for different tetracycline antibiotics.

\begin{tabular}{cccccc}
\hline $\begin{array}{c}\text { Calibration } \\
\text { Parameter }\end{array}$ & ISM & CTC & DXC & OTC & TTC \\
\hline Slope $^{\mathrm{a}}, \mathrm{mV} \mathrm{dec}^{-1}$ & $\mathrm{~A}$ & $62.5 \pm 1.1$ & $58.6 \pm 0.9$ & $54.0 \pm 0.6$ & $52.9 \pm 1.6$ \\
& $\mathrm{~B}$ & $63.4 \pm 2.1$ & $59.0 \pm 0.1$ & $56.2 \pm 0.9$ & $53.8 \pm 2.2$ \\
\hline Linear response $_{\text {range, } \mathrm{M}}$ & $\mathrm{A}$ & $3.0 \times 10^{-7}-1.0 \times 10^{-3}$ & $3.0 \times 10^{-7}-1.0 \times 10^{-3}$ & $6.0 \times 10^{-6}-1.0 \times 10^{-3}$ & $1.0 \times 10^{-6}-1.0 \times 10^{-3}$ \\
& $\mathrm{~B}$ & $3.0 \times 10^{-7}-1.0 \times 10^{-3}$ & $3.0 \times 10^{-7}-1.0 \times 10^{-3}$ & $6.0 \times 10^{-6}-1.0 \times 10^{-3}$ & $1.0 \times 10^{-6}-1.0 \times 10^{-3}$ \\
\hline Limit of $^{-3}$ & $\mathrm{~A}$ & $(1.3 \pm 0.6) \times 10^{-7}$ & $(1.7 \pm 0.3) \times 10^{-7}$ & $(2.9 \pm 0.0) \times 10^{-6}$ & $(3.6 \pm 0.2) \times 10^{-7}$ \\
detection $^{\text {a }}, \mathrm{M}$ & $\mathrm{B}$ & $(1.5 \pm 1.3) \times 10^{-7}$ & $(1.8 \pm 0.7) \times 10^{-7}$ & $(2.5 \pm 0.0) \times 10^{-6}$ & $(4.3 \pm 0.5) \times 10^{-7}$ \\
\hline
\end{tabular}

a Standard deviation value was calculated from three subsequent calibrations of the same electrode.

Nonetheless, regarding the application of the potentiometric sensor in liquid chromatography, the dynamic response characteristics of the TC-selective electrodes must be emphasized, since they can affect the analytical performance under hydrodynamic flow analysis [48]. An important aspect concerns the response time, which has a major impact under transient flow injections due to the short time of interaction between the analytes and the membrane surface. The response time for each of the TCs was determined following IUPAC recommendation [49] at concentrations ranging from $1.0 \times 10^{-7}$ to $1.0 \times 10^{-3} \mathrm{M}$. As expected, a fast response was obtained for higher TC concentrations, especially for ISE containing $\mathrm{CB}[8]$ as an ionophore ( $<10 \mathrm{~s}$, ISM B). However, longer response times were observed at concentrations lower than $1.0 \times 10^{-6} \mathrm{M}(<30 \mathrm{~s})$, though still lower than those obtained with the ionophore-free sensing membrane ( $<60 \mathrm{~s}$, ISM A).

On the other hand, attending to the complexation ability of $\mathrm{CB}[8]$ with the TCs, the reduction in the free energy $\left(\Delta \mathrm{G}_{\text {complex }}\right)$ in the presence of the host molecule should, in principle, generate a larger signal when used under transient flow injections. As such, improved sensitivity and detectability can be attained, which was already demonstrated by other authors dealing with potentiometric detection in liquid chromatography [50,51].

Therefore, the use of $\mathrm{CB}[8]$ as an ionophore for the development of a new TC-selective electrode, highlighting its ability to detect different TCs with great analytical features and a short response time, foresees its application as a detector in a liquid chromatographic system for food control.

\subsection{Evaluation of the Miniaturized TC-Selective Electrode Coupled to HPLC System}

After the characterization of the potentiometric sensors in batch conditions, the miniaturized TC-selective electrodes were assembled in a microfluidic wall-jet flow-cell and coupled to the HPLC system. Several experimental conditions such as (i) the composition of the mobile phase; (ii) gradient program, including hydrodynamic conditions; (iii) incorporation of nanostructured materials into the ISM, were optimized to achieve the best chromatographic separation conditions of the four TCs without compromising the sensitivity and detectability [43].

\subsubsection{Optimization of Mobile Phase Composition}

Various elution solvents were first investigated under isocratic conditions at a fixed flow rate of $1.0 \mathrm{~mL} \mathrm{~min}{ }^{-1}$, namely by evaluating different mixtures of aqueous acid solutions (phosphoric, oxalic, hydrochloric, or sulphuric acid) with ACN $(80: 20, v / v)$. While phosphoric, oxalic, and hydrochloric acid concentrations were prepared at $0.05 \mathrm{M}$, sulphuric acid was prepared at $0.005 \mathrm{M}$, and the $\mathrm{pH}$ was adjusted to 2.0 using $\mathrm{HCl} / \mathrm{NaOH}$ solution. As shown in Figure S3A, the lowest retention factor $(\mathrm{k})$ values were achieved for sulphuric acid, ranging from 0.7 to 5.0 for OTC and DXC, respectively, which enabled a shorter analysis time. Moreover, the separation factor $(\alpha)$ was determined for two subsequent peaks and no effect was noticed when changing the acid agent (Figure S3B). Therefore, aqueous sulphuric acid was selected as an acidifying agent and, moreover, 
the content of $\operatorname{ACN}(10,20$, and $30 \%, v / v)$ was investigated under isocratic conditions. However, a lack of chromatographic selectivity or an increase in the analysis time was observed. To surpass this constraint, gradient elution was considered.

For that, two solvents were selected containing $0.005 \mathrm{M}$ of $\mathrm{H}_{2} \mathrm{SO}_{4}$ and $\mathrm{ACN}$ at a different proportion (A: 90:10; B: 80:20; $v / v$ ). Several combinations of the time/mobile phase composition were carried out to optimize the chromatographic separation in terms of resolution and running time as well as to obtain the best analytical performance of the potentiometric detector. In HPLC-ISE methodologies, a compromise between the optimal separation and detection conditions should be expected because of the impact of the mobile phase composition in the potentiometric detector rather than the spectroscopic detectors.

\subsubsection{Optimization of Hydrodynamic Conditions}

The flow rate and sample injection volume were optimized to obtain the best separation and detection conditions, adjusting the gradient elution whenever necessary. For that, different flow rates $\left(1.0,1.3\right.$, and $\left.1.5 \mathrm{~mL} \mathrm{~min}^{-1}\right)$ were firstly examined by the triplicate injection of standard solutions of TCs at $1.0 \times 10^{-6}, 1.0 \times 10^{-5}$, and $1.0 \times 10^{-4} \mathrm{M}$. According to the chromatograms, the retention times of OTC and DXC (i.e., first and last peak eluted, respectively) were reduced from $12.2 / 31.8 \mathrm{~min}$ to $9.8 / 24.6 \mathrm{~min}$ and $8.4 / 22.5 \mathrm{~min}$ when the flow rate was $1.0,1.3$, and $1.5 \mathrm{~mL} \mathrm{~min}^{-1}$, respectively, without significant effect in the retention and separation factors. Nevertheless, higher flow rates improved the peak resolution $\left(R_{S}\right)$ through an increase in the effective plate number $\left(N_{\text {eff }}\right)$, though affecting the potentiometric detector performance. In this context, when the flow rate changed from 1.0 to $1.3 \mathrm{~mL} \mathrm{~min}^{-1}$, an increase in the signal magnitude (i.e., peak height in $\mathrm{mV}$ ) was observed for all target TCs (see Figure S4), which is ascribed to the wall-jet flow-cell configuration [52]. On the other hand, the shorter residence time of the analyte plug in the microfluidic flow-cell, combined with the longer response time of the electrode, negatively affected the peak heights for the higher flow rate [53]. Therefore, a flow rate of $1.3 \mathrm{~mL} \mathrm{~min}^{-1}$ was selected as the most suitable condition regarding the TCs separation and the detector performance. Overall, the optimal conditions allowed a complete separation of four TCs in less than $24.0 \mathrm{~min}$, following the gradient program: 0\% B from 0 to $13.00 \mathrm{~min}$; 0-100\% B from 13.00 to $13.01 \mathrm{~min} ; 100 \%$ B from 13.01 to $24.00 \mathrm{~min} ; 100-0 \%$ B from 24.00 to $24.01 \mathrm{~min}$. The OTC and TTC were firstly eluted in solvent A, presenting retention times of 9.3 and $12.9 \mathrm{~min}$, respectively. The strong interaction of CTC and DXC with the stationary phase required an increase in the ACN content for an efficient elution, attaining retention times of 21.1 and 24.5, respectively. Nevertheless, ACN content higher than $20 \%(v / v)$ was not considered in this study to avoid the dissolution of the membrane components [50].

On a similar basis, the effect of the injection volume $(20,50$, and $100 \mu \mathrm{L})$ was investigated. As shown in Figure S5, a positive correlation was observed between the injection volume and the peak height for all the studied compounds. While an increase in the peak height was observed for CTC and DXC along with the increasing injection volume, the response for OTC and TTC only improved until $50 \mu \mathrm{L}$. Notably, the magnitude of the signal was very similar for injection volumes of 50 and $100 \mu \mathrm{L}$, which suggest either sample overload or a slow detector response. To obtain the sensitivity and LOD desired for a simultaneous determination of four TCs in milk samples, $100 \mu \mathrm{L}$ volume was selected.

The analytical parameters of the proposed TC-selective electrodes under flow conditions are slightly different than those obtained in static measurements (Table S1, ISM B). Under flow conditions, the residence and response time, the rate of diffusion and the exchange reaction of the eluent ions, the sample dispersion and dilution, namely in flow-cell, affects the analytical performance of the proposed potentiometric detector, as has already been reported by other authors [22,48,53-55]. To overtake these constraints, the use of carbon nanotubes in the sensing membrane was considered. 


\subsubsection{Effect of Carbon Nanotubes}

Carbon nanotubes have been widely used as nanostructured materials in electrochemical sensors' preparation because of their remarkable properties such as large surface-areato-volume ratio, mechanical strength, chemical stability, and excellent electrical conductivity [56]. Their use has been associated with gains in the analytical performance of sensors, namely in LOD, sensitivity, and medium-term stability [57]. In this work, the incorporation of MWCNTs in the ISM was investigated at different proportions $(0.0,1.0$, and $2.0 \mathrm{wt} \%$, see Table 1), and the general calibration parameters of the potentiometric sensors for the target TCs were evaluated under the optimal chromatographic conditions. As shown in Table 3, the incorporation of the MWCNTs (ISM C and D) improved the analytical features of the TC-selective electrodes, evidenced by the better slopes, LODs (calculated as a signal-tonoise ratio of 3), and repeatability of the peak heights for all the analytes. Their electrostatic interaction and hydrogen bonding with the target TCs as well as their contribution to improve the double-layer capacitance of the conductive surface of the electrode where the ion-to-electron transduction takes place allowed for the improvement of the magnitude of the signals within the linear response range by decreasing the response time [58], which contributed to an increase in the slope (comparing ISM B and ISM C in Table 3). However, it was not enough to reach the steady-state signal at the optimal measuring conditions, and, thus, the slopes were still lower than those obtained in static measurements (Table 2), especially for OTC, TTC, and DXC. Attending to the absence of a proper nomenclature of potentiometric detection in hydrodynamic separation systems, the LOD was calculated as generally defined in HPLC, using a signal-to-noise ratio of 3 [59]. Nevertheless, the LOD values determined following the IUPAC recommendation were also calculated [49] (see Table S2). When using the signal-to-noise approach, the LODs observed for the TCs with the ISM containing $1.0 \mathrm{wt} \%$ of MWCNTs (ISM C) were shifted to values below the MRL in milk defined by food authorities, attaining values down to $3.0 \times 10^{-8} \mathrm{M}$ for TTC, CTC, and DXC, and $1.0 \times 10^{-7} \mathrm{M}$ for OTC. Moreover, the improved repeatability of the analytical signal $\left(1.0 \times 10^{-4} \mathrm{M}, \mathrm{n}=3\right)$ was demonstrated by the RSD values of $0.2-5.8 \%$ against $0.4-42.1 \%$ in the electrodes prepared without MWCNTs (ISM B). However, when the proportion of MWCTNs was duplicated (ISM D), no gains were attained, and thus the TC-selective electrode prepared with the ISM C was selected for validation purposes.

Table 3. Effect of the incorporation of MWCNTs in the analytical performance of the miniaturized TC-selective electrodes coupled in the HPLC system.

\begin{tabular}{|c|c|c|c|c|c|c|}
\hline Calibration Parameter & ISM & MWCNTs (wt \%) & отС & TTC & CTC & DXC \\
\hline \multirow{3}{*}{ Slope $^{\mathrm{a}}, \mathrm{mV} \mathrm{dec}^{-1}$} & $\mathrm{~A}$ & 0.0 & $11.2 \pm 0.3$ & $24.9 \pm 5.8$ & $34.7 \pm 6.2$ & $21.0 \pm 7.0$ \\
\hline & $\mathrm{B}$ & 1.0 & $14.5 \pm 0.3$ & $31.0 \pm 3.4$ & $53.1 \pm 5.5$ & $41.3 \pm 1.4$ \\
\hline & $\mathrm{C}$ & 2.0 & $13.9 \pm 2.3$ & $33.0 \pm 4.5$ & $52.4 \pm 6.5$ & $41.5 \pm 3.0$ \\
\hline \multirow{3}{*}{ Limit of detection ${ }^{b}, M$} & $\mathrm{~A}$ & 0.0 & $1.0 \times 10^{-7}$ & $1.0 \times 10^{-7}$ & $1.0 \times 10^{-7}$ & $1.0 \times 10^{-7}$ \\
\hline & B & 1.0 & $1.0 \times 10^{-7}$ & $3.0 \times 10^{-8}$ & $3.0 \times 10^{-8}$ & $3.0 \times 10^{-8}$ \\
\hline & $\mathrm{C}$ & 2.0 & $1.0 \times 10^{-7}$ & $1.0 \times 10^{-7}$ & $1.0 \times 10^{-7}$ & $1.0 \times 10^{-7}$ \\
\hline \multirow{3}{*}{ Precision ${ }^{\mathrm{c}}, \mathrm{RSD}^{\circ} \textrm{ }$} & A & 0.0 & 0.4 & 18.6 & 19.7 & 42.1 \\
\hline & $\mathrm{B}$ & 1.0 & 5.8 & 0.2 & 3.4 & 1.8 \\
\hline & $\mathrm{C}$ & 2.0 & 4.8 & 2.5 & 5.2 & 1.7 \\
\hline
\end{tabular}

a Standard deviation value was calculated from three subsequent calibrations of the same electrode. ${ }^{\mathrm{b}}$ Based on a signal-to-noise ratio of $3 .{ }^{\mathrm{c}}$ Repeatability of the peak height calculated after triplicate injection of solution at $1.0 \times 10^{-4} \mathrm{M}$.

\subsection{Method Validation}

The chromatographic parameters of the proposed HPLC method coupled to the potentiometric and UV detector are summarized in Tables S3 and S4, respectively, namely retention times $\left(t_{R}\right)$, retention factor $(k)$, separation factor $(\alpha)$, effective plate number $\left(\mathrm{N}_{\text {eff }}\right)$, peak resolution $\left(\mathrm{R}_{\mathrm{s}}\right)$, and tailing factor $\left(\mathrm{T}_{\mathrm{f}}\right)$. The repeatability of retention times showed excellent results, providing RSD values lower than $2.6 \%$ after the analysis in five 
independent days. The retention factors were fairly good, ranging from 1.2 to 1.6 for both types of detectors. The higher effective plate number obtained for CTC and DXC presented better separation efficiency, which is ascribed to the higher content of ACN during their elution. However, a slightly smaller value was obtained for all target TCs with the HPLCISE methodology, which may be attributed to the adsorption/desorption phenomena of the analytes at the membrane surface of the TC-selective electrode $[22,60]$. This fact also explains the differences obtained in the peak symmetry, demonstrated by the tailing factors of 1.4 to 1.6 and 1.1 to 1.2 for potentiometric and UV detectors, respectively. Although an increase in the ACN content in the mobile phase could accelerate the rate of dissociation (i.e., desorption phenomena) [22], it was not considered to avoid the dissolution of the membrane components. Overall, great peak resolution values were obtained for both types of detectors, ranging from 6.3 to 13.8 and from 7.4 to 16.0 for potentiometric and UV types, respectively, which are above the acceptable criteria $(\geq 1.5)$.

\subsubsection{Analytical Figures of Merit}

The optimized method was validated according to the requirements of the International Council for Harmonisation of Technical Requirements for Pharmaceuticals for Human Use (ICH) [61] and the European Union (EU) [62] by evaluating the following analytical parameters: linear range, linearity, the limit of detection (LOD), the limit of quantitation (LOQ), precision, accuracy, and specificity. The results of the potentiometric detector are summarized in Table 4, while those obtained with the UV detector are in Table S5.

Table 4. Analytical figures of merit obtained with the proposed TC-selective electrode as detector in HPLC.

\begin{tabular}{|c|c|c|c|c|}
\hline $\begin{array}{l}\text { Validation } \\
\text { Parameter }\end{array}$ & OTC & TTC & СТC & DXC \\
\hline Calibration curve & \multicolumn{4}{|c|}{ tR vs. [TC] $\mu \mathrm{M}$} \\
\hline Linear range, $\mathrm{M}$ & $2.0 \times 10^{-7}-1.0 \times 10^{-5}$ & $1.0 \times 10^{-7}-1.0 \times 10^{-5}$ & $1.0 \times 10^{-7}-1.0 \times 10^{-5}$ & $1.0 \times 10^{-7}-1.0 \times 10^{-5}$ \\
\hline Slope & $63.4 \pm 2.1$ & $59.0 \pm 0.1$ & $56.2 \pm 0.9$ & $53.8 \pm 2.2$ \\
\hline Intercept & $0.9987 \pm 0.0003$ & $0.9988 \pm 0.0010$ & $0.9993 \pm 0.0001$ & $0.9991 \pm 0.0000$ \\
\hline$R^{2}$ & $0.9987 \pm 0.0012$ & $0.9986 \pm 0.0006$ & $0.9973 \pm 0.0026$ & $0.9983 \pm 0.0027$ \\
\hline $\mathrm{LOD}, \mathrm{M}\left(\mu \mathrm{g} \mathrm{L}^{-1}\right)$ & $1.0 \times 10^{-7}(46.0)$ & $3.0 \times 10^{-8}(13.3)$ & $3.0 \times 10^{-8}(14.4)$ & $3.0 \times 10^{-8}(13.3)$ \\
\hline $\mathrm{LOQ}, \mathrm{M}\left(\mu \mathrm{g} \mathrm{L}^{-1}\right)$ & $2.0 \times 10^{-7}(92.1)$ & $1.0 \times 10^{-7}(44.4)$ & $1.0 \times 10^{-7}(47.9)$ & $1.0 \times 10^{-7}(44.4)$ \\
\hline \multicolumn{5}{|l|}{ Precision, RSD\% } \\
\hline & \multicolumn{4}{|c|}{ Intra-day } \\
\hline $3.0 \times 10^{-7} \mathrm{M}$ & 10.2 & 7.9 & 12.5 & 7.4 \\
\hline $1.0 \times 10^{-6} \mathrm{M}$ & 6.0 & 8.3 & 6.7 & 6.6 \\
\hline $1.0 \times 10^{-5} \mathrm{M}$ & 6.6 & 4.1 & 7.1 & 4.9 \\
\hline & \multicolumn{4}{|c|}{ Inter-day } \\
\hline $3.0 \times 10^{-7} \mathrm{M}$ & 4.4 & 11.7 & 13.1 & 13.5 \\
\hline $1.0 \times 10^{-6} \mathrm{M}$ & 1.6 & 10.0 & 7.2 & 4.9 \\
\hline $1.0 \times 10^{-5} \mathrm{M}$ & 1.7 & 3.7 & 5.1 & 7.2 \\
\hline & \multicolumn{4}{|c|}{ Inter-electrode } \\
\hline $3.0 \times 10^{-7} \mathrm{M}$ & 12.0 & 10.7 & 5.1 & 2.9 \\
\hline $1.0 \times 10^{-6} \mathrm{M}$ & 5.9 & 9.4 & 8.3 & 12.9 \\
\hline $1.0 \times 10^{-5} \mathrm{M}$ & 6.2 & 3.7 & 8.9 & 6.2 \\
\hline
\end{tabular}

The calibration curves were assessed by the injection of standard solutions of TCs at concentration levels in the range of $1.0 \times 10^{-8}-1.0 \times 10^{-4} \mathrm{M}(\mathrm{n}=8)$, and the corresponding chromatograms are presented in Figure S5A,B for the potentiometric and UV detector, respectively. A transformed response $t R=10^{(E S)}-1$, where $E$ is the potentiometric signal in $\mathrm{mV}$ and $\mathrm{S}$ is the slope of the Nikolsky-Eisenman equation, was used as the analytical signal of the potentiometric detector and plotted against the TCs' concentration [63]. Linear regression lines were obtained for TTC, CTC, and DXC in the range from $1.0 \times 10^{-7}$ to $1.0 \times 10^{-5} \mathrm{M}$ while, for OTC, it was in the range from $2.0 \times 10^{-7}$ to $1.0 \times 10^{-5} \mathrm{M}$, with 
coefficients of determination $\left(\mathrm{R}^{2}\right) \geq 0.9973$. Regarding the UV detector, the peak area was used as an analytical signal and plotted against the TCs' concentrations, attaining linear regression for all target TCs in the range from $1.0 \times 10^{-8}$ to $1.0 \times 10^{-5} \mathrm{M}$, with coefficients of determination $\left(\mathrm{R}^{2}\right) \geq 0.9977$.

The LOD and LOQ of the potentiometric detector were determined as the lowest injected concentration of the TCs giving a signal-to-noise ratio of 3 and 10, respectively, while the standard deviation of the blank and the slope of the calibration curve was used for the UV detector. In the former, LOD and LOQ values were $1.0 \times 10^{-7}$ and $2.0 \times 10^{-7} \mathrm{M}$ for OTC, whereas, for TTC, CTC, and DXC, they were $3.0 \times 10^{-8}$ and $1.0 \times 10^{-7} \mathrm{M}$, respectively. These values correspond to a range of 13.3 to $46.0 \mu \mathrm{g} \mathrm{L}^{-1}$ and 44.4 to $92.1 \mu \mathrm{g} \mathrm{L}^{-1}$ for LOD and LOQ, respectively. For comparison, the LOD and LOQ values obtained with the UV detector were $3.0 \times 10^{-9}$ and $1.0 \times 10^{-8} \mathrm{M}$ for all target TCs, respectively. Nonetheless, as far as the authors know, this is the very first TC-selective electrode, coupled to HPLC, capable of determining TCs' residues around the MRL level $\left(100 \mu \mathrm{g} \mathrm{L}^{-1}\right)$.

The precision of the HPLC method was assessed by the triplicate injection of standard solutions of TCs at concentrations of $3.0 \times 10^{-7}, 1.0 \times 10^{-6}$, and $1.0 \times 10^{-5} \mathrm{M}$ on the same day and on three different days. The intra- and inter-day precision results were expressed by the RSD of the potentiometric and absorbance signal at each concentration level (Table 4 and Table S5). In the intra-day, the RSD ranged from 7.4 to $10.2 \%, 6.0$ to $8.3 \%$, and 4.1 to $7.1 \%$ for the potentiometric detector, while, for the UV detector, it ranged from 4.4 to $8.2 \%, 3.7$ to $4.2 \%$, and 2.9 to $4.2 \%$ at increasing TC concentration, respectively. Regarding the inter-day precision, the RSD ranged from 4.4 to $13.5 \%, 1.6$ to $10.0 \%$, and 4.1 to $7.1 \%$ for the HPLC-POT, while for the HPLC-UV, it ranged from 6.1 to $11.5 \%, 5.3$ to $19.1 \%$, and 1.2 to $11.4 \%$, respectively. The variations obtained for all the tested compounds agree with the European requirements because they are lower than $20 \%$ and $10 \%$ for the applied target concentrations, proving the great precision of the method [62]. Moreover, in the case of the potentiometric detector, the inter-electrode reproducibility $(n=3)$ was also evaluated on a similar basis, and showed RSD values for the analytical signal ranging from 2.9 to $12.0 \%, 5.9$ to $12.9 \%$, and 3.7 to $8.9 \%$ at concentrations of $3.0 \times 10^{-7}, 1.0 \times 10^{-6}$, and $1.0 \times 10^{-5} \mathrm{M}$ respectively.

\subsubsection{Application in Real Sample Analysis}

To assess the accuracy and applicability of the proposed method, different milk samples containing $0,50,100$, or $200 \mu \mathrm{g} \mathrm{L}^{-1}$ of standard solution were analyzed concerning the four TCs. The recoveries were calculated according to the following equation:

$$
\text { Recovery }(\%)=\left[\left(\mathrm{TC}_{\text {Found }}-\mathrm{TC}_{\text {Initial }}\right) / \mathrm{TC}_{\text {Spiked }}\right] \times 100
$$

in which $\mathrm{TC}_{\text {Found }}$ is the concentration of TCs measured in the extracts of the spiked milk samples, $\mathrm{TC}_{\text {Initial }}$ is the intrinsic concentration of $\mathrm{TC}$ in milk samples, and $\mathrm{TC}_{\text {Spiked }}$ is the amount of TCs added to the milk samples. As observed in Table 5, TCs were not found in the collected milk samples and the recoveries ranged from 87.1 to $102.3 \%, 81.3$ to $108.5 \%$, and 84.1 to $103.9 \%$ in UHT skimmed milk, UHT semi-skimmed milk, and fresh semi-skimmed milk samples, respectively, with overall RSDs lower than 9.6\%. These obtained values prove the required accuracy imposed by the European requirements, which only accept recovery values within the range between $80 \%$ and $110 \%$ for the applied target concentrations [62]. For comparison purposes, the spiked milk samples were also analyzed with the UV detector and the obtained concentrations of the two groups were equal as statically demonstrated by the calculated $p$-values for the bilateral $t$-test with a 95\% confidence level (Table S6). 
Table 5. Recovery values of the proposed HPLC-POT for the determination of TCs in spiked milk samples ( $\mathrm{n}=3$ for each concentration).

\begin{tabular}{|c|c|c|c|c|c|c|c|c|c|c|}
\hline \multirow[b]{2}{*}{ Analytes } & \multirow{2}{*}{$\begin{array}{l}\text { Added } \\
\mu \mathrm{g} \mathrm{L}^{-1}\end{array}$} & \multicolumn{3}{|c|}{ UHT Skimmed Milk } & \multicolumn{3}{|c|}{ UHT Semi-Skimmed Milk } & \multicolumn{3}{|c|}{ Fresh Semi-Skimmed Milk } \\
\hline & & $\begin{array}{l}\text { Found } \\
\mu g L^{-1}\end{array}$ & $\begin{array}{c}\text { RSD } \\
\%\end{array}$ & $\begin{array}{l}\text { RV } \\
\%\end{array}$ & $\begin{array}{l}\text { Found } \\
\mu g L^{-1}\end{array}$ & $\begin{array}{c}\text { RSD } \\
\%\end{array}$ & $\begin{array}{l}\text { RV } \\
\%\end{array}$ & $\begin{array}{l}\text { Found } \\
\mu g L^{-1}\end{array}$ & $\begin{array}{c}\text { RSD } \\
\%\end{array}$ & $\begin{array}{l}\mathrm{RV} \\
\%\end{array}$ \\
\hline \multirow{4}{*}{ OTC } & 0 & N.D. & - & - & N.D. & - & - & N.D. & - & - \\
\hline & 50 & $<\mathrm{LOQ}$ & - & - & $<\mathrm{LOQ}$ & - & - & $<\mathrm{LOQ}$ & - & - \\
\hline & 100 & $100.1 \pm 3.2$ & 3.2 & 100.1 & $103.3 \pm 4.9$ & 4.8 & 103.3 & $98.0 \pm 6.9$ & 7.1 & 98.0 \\
\hline & 200 & $204.6 \pm 10.7$ & 5.2 & 102.3 & $178.0 \pm 6.2$ & 3.5 & 89.0 & $180.4 \pm 15.0$ & 8.3 & 90.2 \\
\hline \multirow{4}{*}{ TTC } & 0 & N.D & - & - & N.D & - & - & N.D & - & - \\
\hline & 50 & $49.1 \pm 4.2$ & 8.6 & 98.3 & $50.1 \pm 1.4$ & 2.8 & 100.1 & $51.9 \pm 1.6$ & 3.1 & 103.8 \\
\hline & 100 & $91.0 \pm 6.1$ & 6.7 & 91.0 & $87.7 \pm 5.3$ & 6.0 & 87.7 & $84.1 \pm 3.2$ & 3.8 & 84.1 \\
\hline & 200 & $174.3 \pm 16.8$ & 9.6 & 87.1 & $194.4 \pm 8.6$ & 4.4 & 97.2 & $183.1 \pm 13.9$ & 7.6 & 91.5 \\
\hline \multirow{4}{*}{ СТC } & 0 & N.D & - & - & N.D & - & - & N.D & - & - \\
\hline & 50 & $46.9 \pm 3.0$ & 6.4 & 93.8 & $47.6 \pm 1.2$ & 2.6 & 95.2 & $49.2 \pm 3.0$ & 6.1 & 98.4 \\
\hline & 100 & $88.5 \pm 7.9$ & 8.9 & 88.5 & $88.7 \pm 2.0$ & 2.3 & 88.7 & $103.9 \pm 4.5$ & 4.3 & 103.9 \\
\hline & 200 & $197.0 \pm 15.4$ & 7.8 & 98.5 & $192.4 \pm 5.6$ & 2.9 & 96.2 & $185.4 \pm 11.5$ & 6.2 & 92.7 \\
\hline \multirow{4}{*}{ DXC } & 0 & N.D & - & - & N.D & - & - & N.D & - & - \\
\hline & 50 & $45.9 \pm 3.2$ & 6.9 & 91.8 & $48.5 \pm 2.1$ & 4.3 & 96.9 & $44.1 \pm 1.9$ & 4.3 & 88.2 \\
\hline & 100 & $95.6 \pm 2.0$ & 2.1 & 95.6 & $108.5 \pm 2.1$ & 1.9 & 108.5 & $88.1 \pm 3.1$ & 3.5 & 88.1 \\
\hline & 200 & $190.1 \pm 12.2$ & 6.4 & 95.0 & $162.7 \pm 6.8$ & 4.2 & 81.3 & $177.4 \pm 10.7$ & 6.0 & 88.7 \\
\hline
\end{tabular}

N.D.-Not detected; RV—Recovery (\%).

To complete the method validation, the specificity was evaluated by comparing the chromatograms of the extracts obtained from spiked samples with those obtained from blank milk samples and working standard solutions containing a mixture of all TCs. Figure 2 demonstrates that no interference between the matrix endogenous substances and the target TCs was found for the fresh semi-skimmed milk samples.

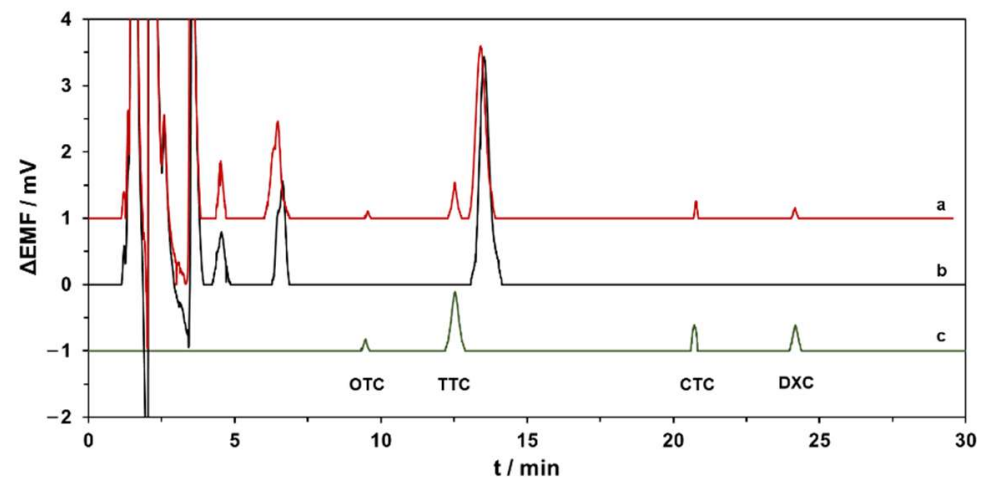

Figure 2. Chromatograms obtained with the proposed HPLC-ISE method after the injection of (a) extract of fresh semi-skimmed milk spiked at $100 \mu \mathrm{g} \mathrm{L}^{-1}$ (MRL level); (b) extract of blank fresh semi-skimmed milk; (c) standard solution of TCs at $3.0 \times 10^{-7} \mathrm{M}\left(\approx 140 \mu \mathrm{g} \mathrm{L}^{-1}\right)$.

\subsection{Comparison of the Proposed Method with Other Conventional Methods Reported in the Literature}

The performance and the advantages of the herein proposed HPLC-ISE method were compared with the most recent methods based on HPLC for the determination of TCs residues in milk samples (see Table S7). By comparing the analytical features, sample volume, and instrumental technique, the LC-MS/MS methods are strengthened by their powerful resolution, selectivity, and sensitivity $[11,12]$. Among those advantages, MS/MSbased methods also allow multiclass detection $[13,64]$, though the higher price of acquisition and maintenance, combined with the need for specialized human resources, limit their use in routine analysis for food quality control laboratories. Notably, the LOD/LOQ obtained 
with the proposed method enabled the determination of TCs below the MRL without a preconcentration step, which favorably contrasts with HPLC-UV methods [65,66]. As such, the possibility of reducing the volume of the sample, and especially of the reagents during the determination, makes it a greener methodology. On the other hand, the HPLCISE method demonstrated great accuracy (recoveries from 81.3 to $108.5 \%$ ) and precision (RSD $<9.6 \%$ ) in the determination of TCs' residues around the MRL level in milk. Moreover, the simplicity and cost-effectiveness of the proposed potentiometric detector enhanced its use as an easy and affordable alternative to routine detectors.

Concerning the efficiency of the extraction method, the proposed SPE with OASIS PRIME HLB cartridges attained comparable and, in some cases, better recoveries than those of the other methods $[67,68]$. However, the total analysis time (extraction and separation) was higher than other innovative procedures based on liquid microextraction [69,70], matrix solid-phase dispersion [71], and online SPE [72], though was comparable with those based on conventional SPE with OASIS HLB $[67,68]$.

Overall, the proposed method provided a straightforward alternative for the determination of TCs in milk samples, and, to the best of our knowledge, this is the very first TC-selective electrode, coupled to HPLC, capable of determining TCs' residues around the MRL level $\left(100 \mu \mathrm{g} \mathrm{L}^{-1}\right)$. Additionally, the portability and miniaturization ability of potentiometric sensors, combined with innovative sample operation techniques and the downsizing of chromatographic columns, will certainly leverage the development of an integrated lab-on-chip platform for the remote screening of TCs in food samples.

\section{Conclusions}

In the present work, the use of cucurbit[8]uril as a macrocyclic receptor improved the analytical features (i.e., LOD, sensitivity, and precision) already described for other tetracycline-selective electrodes with different ionophores. Moreover, the incorporation of multi-walled carbon nanotubes as nanostructured materials in the sensing membrane improved the detection limit as well as the repeatability of the analytical signal of the potentiometric detector under the optimized chromatographic conditions.

Therefore, a simple, cost-effective, and reliable HPLC-ISE method is proposed for the simultaneous determination of four tetracycline antibiotics in milk samples at levels around the maximum residue limits within an analysis time of $30 \mathrm{~min}$. Noteworthy, the advantages of the proposed method highlight its competitiveness towards the currently used methods, based on HPLC with diode-array and mass spectrometry detection, for the routine analysis of tetracycline residues in food samples.

Supplementary Materials: The following supporting information can be downloaded at: https: / / www.mdpi.com/article/10.3390/chemosensors10030098/s1, Details on the potentiometric measurements. Figure S1: Dynamic potentiometric responses for ion-selective electrodes prepared without (ISM A) and with CB[8] (ISM B) in batch conditions at the increasing concentration of chlortetracycline (CTC), doxycycline (DXC), oxytetracycline (OTC), and tetracycline (TTC); Figure S2: Calibration curves of EMF responses of CTC, DXC, OTC, and TTC obtained with the ion-selective electrodes prepared without (ISM A) and with CB[8] (ISM B) in batch conditions; Figure S3: Effect of the acidifying agent of the mobile phase in the (A) capacity and (B) selectivity factors; Figure S4: Detector performance (peak heights in $\mathrm{mV}$ ) for standard solutions of four tetracycline antibiotics at $1.0,10.0$, and $100.0 \mu \mathrm{M}$ as a function of the mobile phase flow rate; Figure S5: Detector performance (peak heights in $\mathrm{mV}$ ) for standard solutions of four tetracycline antibiotics at 1.0, 10.0, and $100.0 \mu \mathrm{M}$ as a function of the injection volume; Figure S6: Chromatograms at increasing concentrations (0.1, $0.3,1.0,3.0,10.0,100.0 \mu \mathrm{M})$ of tetracycline antibiotics obtained with the proposed tetracycline potentiometric detector (A) and the UV detector (wavelength $355 \mathrm{~nm}$ ) in HPLC. Table S1: Linear fittings (EMF response in $\mathrm{mV}$ versus logarithmic concentration) for the tetracycline-selective electrode (ISM B) in batch and flow conditions; Table S2: Limits of detection (calculated by IUPAC recommendation [49]) of the miniaturized TC-selective electrodes prepared with different amount of MWCNTs; Table S3: Chromatographic parameters of the target tetracycline antibiotics using the proposed HPLC-potentiometric method; Table S4: Chromatographic parameters of the target tetracycline 
antibiotics using the HPLC-UV method; Table S5: Analytical figures of merit obtained with the proposed HPLC method using the UV detector ( $355 \mathrm{~nm}$ ); Table S6: Results obtained for determination of tetracycline antibiotics in spiked milk samples by HPLC using the proposed potentiometric detector compared with the UV detector ( $\mathrm{n}=3$ for each concentration); Table S7: Comparison of the proposed method with other published methods for the determination of tetracycline antibiotics in milk samples [11,13,65-72].

Author Contributions: Conceptualization, R.L.G., C.M.P.G.A., M.d.C.B.S.M.M. and A.N.A.; Formal analysis, R.L.G., C.M.P.G.A., M.d.C.B.S.M.M. and A.N.A.; Investigation, R.L.G.; Methodology, C.M.P.G.A.; Resources, M.d.C.B.S.M.M. and A.N.A.; Supervision, C.M.P.G.A., M.d.C.B.S.M.M. and A.N.A.; Validation, R.L.G.; Visualization, R.L.G.; Writing—original draft, R.L.G.; Writing-review and editing, C.M.P.G.A., M.d.C.B.S.M.M. and A.N.A. All authors have read and agreed to the published version of the manuscript.

Funding: This research was financially supported from PT national funds (FCT/MCTES, Fundação para a Ciência e Tecnologia and Ministério da Ciência, Tecnologia e Ensino Superior) through the project UIDB/50006/2020. Renato L. Gil thanks FCT and ESF (European Social Fund) through POCH (Programa Operacional Capital Humano) for his PhD grant SFRH/BD/131504/2017.

Institutional Review Board Statement: Not applicable.

Informed Consent Statement: Not applicable.

Data Availability Statement: Data is available upon written request to authors.

Conflicts of Interest: The authors declare no conflict of interest.

\section{References}

1. Chopra, I.; Roberts, M. Tetracycline Antibiotics: Mode of Action, Applications, Molecular Biology, and Epidemiology of Bacterial Resistance. Microbiol. Mol. Biol. Rev. 2001, 65, 232-260. [CrossRef]

2. Yu, H.; Tao, Y.; Chen, D.; Wang, Y.; Yuan, Z. Development of an HPLC-UV method for the simultaneous determination of tetracyclines in muscle and liver of porcine, chicken and bovine with accelerated solvent extraction. Food Chem. 2011, 124, 1131-1138. [CrossRef]

3. Sczesny, S.; Nau, H.; Hamscher, G. Residue Analysis of Tetracyclines and Their Metabolites in Eggs and in the Environment by HPLC Coupled with a Microbiological Assay and Tandem Mass Spectrometry. J. Agric. Food Chem. 2003, 51, 697-703. [CrossRef] [PubMed]

4. Han, R.; Zheng, N.; Yu, Z.; Wang, J.; Xu, X.; Qu, X.; Li, S.; Zhang, Y. Simultaneous determination of 38 veterinary antibiotic residues in raw milk by UPLC-MS/MS. Food Chem. 2015, 181, 119-126. [CrossRef] [PubMed]

5. Mookantsa, S.; Dube, S.; Nindi, M. Development and application of a dispersive liquid-liquid microextraction method for the determination of tetracyclines in beef by liquid chromatography mass spectrometry. Talanta 2016, 148, 321-328. [CrossRef]

6. Phillips, I. Withdrawal of growth-promoting antibiotics in Europe and its effects in relation to human health. Int. J. Antimicrob. Agents 2007, 30, 101-107. [CrossRef]

7. Food and Drug Administration. Code of Federal Regulations: Title 21 Food and Drugs; FDA: Silver Spring, MD, USA, 2021; Part 556, Sections 150, 500, and 720.

8. Codex Alimentarius Commission of the FAO/WHO. Maximum Residue Limits for Veterinary Drugs in Foods CX/MRL; FAO/WHO: Rome, Italy, 2018; pp. 1-46.

9. Önal, A. Overview on liquid chromatographic analysis of tetracycline residues in food matrices. Food Chem. 2011, 127, 197-203. [CrossRef]

10. Kargin, I.D.; Sokolova, L.S.; Pirogov, A.V.; Shpigun, O.A. HPLC determination of tetracycline antibiotics in milk with post-column derivatization and fluorescence detection. Inorg. Mater. 2016, 52, 1365-1369. [CrossRef]

11. Wei, D.; Wu, S.; Zhu, Y. Magnetic solid phase extraction based on graphene oxide/nanoscale zero-valent iron for the determination of tetracyclines in water and milk by using HPLC-MS/MS. RSC Adv. 2017, 7, 44578-44586. [CrossRef]

12. Igualada, C.; Giraldo, J.; Font, G.; Yusà, V. Validation of a multi-residue UHPLC-HRMS method for antibiotics screening in milk, fresh cheese, and whey. J. Food Compos. Anal. 2022, 106, 104265. [CrossRef]

13. Zhang, L.; Shi, L.; He, Q.; Li, Y. A rapid multiclass method for antibiotic residues in goat dairy products by UPLCquadrupole/electrostatic field orbitrap high-resolution mass spectrometry. J. Anal. Sci. Technol. 2021, 12, 14. [CrossRef]

14. Bobacka, J.; Ivaska, A.; Lewenstam, A. Potentiometric Ion Sensors. Chem. Rev. 2008, 108, 329-351. [CrossRef] [PubMed]

15. Zdrachek, E.; Bakker, E. Potentiometric Sensing. Anal. Chem. 2018, 91, 2-26. [CrossRef] [PubMed]

16. Alexander, P.W.; Haddad, P.R.; Trojanowicz, M. Potentiometric detection in ion chromatography using a metallic copper indicator electrode. Chromatographia 1985, 20, 179-184. [CrossRef] 
17. Haddad, P.; Alexander, P.; Trojanowicz, M. Ion chromatography of Mg, Ca, Sr and Ba ions using a metallic copper electrode as a potentiometric detector. J. Chromatogr. A 1984, 294, 397-402. [CrossRef]

18. Haddad, P.; Alexander, P.; Trojanowicz, M. Ion chromatography of inorganic anions with potentiometric detection using a metallic copper electrode. J. Chromatogr. A 1985, 321, 363-374. [CrossRef]

19. Zielinska, D.; Gil, A.; Pietraszkiewicz, M.; Van De Vijver, D.; Nagels, L. Podand and macrocyclic amine receptors with urea functionalities for potentiometric detection of organic acids in HPLC. Anal. Chim. Acta 2004, 523, 177-184. [CrossRef]

20. Bazylak, G.; Nagels, L.J. Simultaneous high-throughput determination of clenbuterol, ambroxol and bromhexine in pharmaceutical formulations by HPLC with potentiometric detection. J. Pharm. Biomed. Anal. 2003, 32, 887-903. [CrossRef]

21. Vissers, B.; Bohets, H.; Everaert, J.; Cool, P.; Vansant, E.; Du Prez, F.; Kauffmann, J.; Nagels, L. Characteristics of new compositeand classical potentiometric sensors for the determination of pharmaceutical drugs. Electrochim. Acta 2006, 51, 5062-5069. [CrossRef]

22. Daems, D.; Van Camp, G.; Fernandez, M.; Guisez, Y.; Prinsen, E.; Nagels, L. Use of potentiometric detection in (ultra) high performance liquid chromatography and modelling with adsorption/desorption binding kinetics. Anal. Chim. Acta 2013, 777, 25-31. [CrossRef]

23. Füglein, R.; Bräuchle, C.; Hampp, N. Ion-Selective Electrodes for the Determination of the Antibiotic Drug Chlortetracycline Anal. Sci. 1994, 10, 959-962. [CrossRef]

24. El-Ansary, A.; Issa, Y.; Tag-Eldin, A. Tetracycline Sensitive Membrane Electrodes Based on Poly (Vinyl Chloride) Matrices and their use in Drug Analysis. Anal. Lett. 1999, 32, 2177-2190. [CrossRef]

25. Moreira, F.T.; Kamel, A.H.; Guerreiro, J.R.; Sales, M.G.F. Man-tailored biomimetic sensor of molecularly imprinted materials for the potentiometric measurement of oxytetracycline. Biosens. Bioelectron. 2010, 26, 566-574. [CrossRef]

26. Moreira, F.T.C.; Guerreiro, J.R.L.; Azevedo, V.L.; Kamel, A.H.; Sales, M.G.F. New biomimetic sensors for the determination of tetracycline in biological samples: Batch and flow mode operations. Anal. Methods 2010, 2, 2039-2045. [CrossRef]

27. Gai, P.; Guo, Z.; Yang, F.; Duan, J.; Hao, T.; Wang, S. Highly-sensitive ion selective electrode based on molecularly imprinted polymer particles for determination of tetracycline in aqueous samples. Russ. J. Electrochem. 2011, 47, 940-947. [CrossRef]

28. Amorim, C.; Araújo, A.; Montenegro, M.; Silva, V. Cyclodextrin-based potentiometric sensors for midazolam and diazepam. J. Pharm. Biomed. Anal. 2008, 48, 1064-1069. [CrossRef] [PubMed]

29. Shishkanova, T.; Sykora, D.; Sessler, J.; Král, V. Potentiometric response and mechanism of anionic recognition of heterocalixarenebased ion selective electrodes. Anal. Chim. Acta 2007, 587, 247-253. [CrossRef]

30. Ali, T.A.; Ali, T.A.; Mohamed, G.G.; Mohamed, G.G.; El-Sonbati, A.Z.; El-Sonbati, A.Z.; Diab, M.A.; Diab, M.A.; Elkfass, A.M.; Elkfass, A.M. A Potentiometric Sensor for Determination of Doxycycline Hydrochloride in Pharmaceutical Preparation and Biological Fluids. Russ. J. Electrochem. 2018, 54, 1081-1095. [CrossRef]

31. Cunha, C.O.; Silva, R.C.R.; Amorim, C.G.; Júnior, S.A.; Araújo, A.N.; Montenegro, M.C.B.S.M.; Silva, V.L. Tetracycline Potentiometric Sensor Based on Cyclodextrin for Pharmaceuticals and Waste Water Analysis. Electroanalysis 2010, 22, $2967-2972$. [CrossRef]

32. Barrow, S.J.; Kasera, S.; Rowland, M.J.; del Barrio, J.; Scherman, O.A. Cucurbituril-Based Molecular Recognition. Chem. Rev. 2015, 115, 12320-12406. [CrossRef]

33. Lagona, J.; Mukhopadhyay, P.; Chakrabarti, S.; Isaacs, L. The Cucurbit[n]uril Family. Angew. Chem. Int. Ed. 2005, 44, 4844-4870. [CrossRef] [PubMed]

34. Das, D.; Assaf, K.I.; Nau, W.M. Applications of Cucurbiturils in Medicinal Chemistry and Chemical Biology. Front. Chem. 2019, 7 , 619. [CrossRef] [PubMed]

35. Chang, Y.-X.; Qiu, Y.-Q.; Du, L.-M.; Li, C.-F.; Guo, M. Determination of ranitidine, nizatidine, and cimetidine by a sensitive fluorescent probe. Analyst 2011, 136, 4168-4173. [CrossRef] [PubMed]

36. Occello, V.N.S.; Veglia, A.V. Cucurbit[6]uril nanocavity as an enhanced spectrofluorimetric method for the determination of pyrene. Anal. Chim. Acta 2011, 689, 97-102. [CrossRef] [PubMed]

37. Liu, M.; Guo, J.; Shi, L. A ultrastable cucurbit[6] uril-based multifunctional supramolecular assembly for efficient detection of nitroaromatic compounds and antibiotics. New J. Chem. 2021, 45, 18221-18228. [CrossRef]

38. del Pozo, M.; Mejías, J.; Hernández, P.; Quintana, C. Cucurbit[8] uril-based electrochemical sensors as detectors in flow injection analysis. Application to dopamine determination in serum samples. Sens. Actuators B Chem. 2014, 193, 62-69. [CrossRef]

39. Liu, J.; Lambert, H.; Zhang, Y.-W.; Lee, T.-C. Rapid Estimation of Binding Constants for Cucurbit[8]uril Ternary Complexes Using Electrochemistry. Anal. Chem. 2021, 93, 4223-4230. [CrossRef]

40. Cheng, W.; Ma, J.; Kong, D.; Zhang, Z.; Khan, A.; Yi, C.; Hu, K.; Yi, Y.; Li, J. One step electrochemical detection for matrix metalloproteinase 2 based on anodic stripping of silver nanoparticles mediated by host-guest interactions. Sens. Actuators B Chem. 2020, 330, 129379. [CrossRef]

41. Amorim, C.G.; Araújo, A.; Montenegro, M.D.C. Use of Cucurbit[6]uril as Ionophore in Ion Selective Electrodes for Etilefrine Determination in Pharmaceuticals. Electroanalysis 2019, 31, 2171-2178. [CrossRef]

42. Ferreira, C.; Palmeira, A.; Sousa, E.; Amorim, C.G.; Araújo, A.N.; Montenegro, M.C. Supramolecular Atropine Potentiometric Sensor. Sensors 2021, 21, 5879. [CrossRef]

43. Gil, R.L.; Amorim, C.G.; Montenegro, M.C.; Araújo, A.N. Determination of biogenic amines in tomato by ion-pair chromatography coupled to an amine-selective potentiometric detector. Electrochim. Acta 2021, 378, 138134. [CrossRef] 
44. Gil, R.L.; Amorim, C.G.; Montenegro, M.C.; Araújo, A.N. HPLC-potentiometric method for determination of biogenic amines in alcoholic beverages: A reliable approach for food quality control. Food Chem. 2021, 372, 131288. [CrossRef] [PubMed]

45. Waters. 2013. Available online: https://www.waters.com/webassets/cms/library/docs/720004582en.pdf (accessed on 1 July 2021)

46. Wen, Y.; Wang, Y.; Feng, Y.-Q. Simultaneous residue monitoring of four tetracycline antibiotics in fish muscle by in-tube solid-phase microextraction coupled with high-performance liquid chromatography. Talanta 2006, 70, 153-159. [CrossRef] [PubMed]

47. Cuartero, M.; Amorim, C.G.; Araújo, A.N.; Ortuño, J.A.; Montenegro, M.C. A SO 2 -selective electrode based on a Zn-porphyrin for wine analysis. Anal. Chim. Acta 2013, 787, 57-63. [CrossRef] [PubMed]

48. Tóth, K.; Fucskó, J.; Lindner, E.; Fehér, Z.; Pungor, E. Potentiometric detection in flow analysis. Anal. Chim. Acta 1986, 179, 359-370. [CrossRef]

49. Buck, R.P.; Lindner, E. Recommendations for nomenclature of ion-selective electrodes (IUPAC Recommendations 1994). Pure Appl. Chem. 1994, 66, 2527-2536. [CrossRef]

50. Poels, I.; Nagels, L. Potentiometric detection of amines in ion chromatography using macrocycle-based liquid membrane electrodes. Anal. Chim. Acta 2001, 440, 89-98. [CrossRef]

51. Zielinska, D.; Poels, I.; Pietraszkiewicz, M.; Radecki, J.; Geise, H.; Nagels, L. Potentiometric detection of organic acids in liquid chromatography using polymeric liquid membrane electrodes incorporating macrocyclic hexaamines. J. Chromatogr. A 2001, 915, 25-33. [CrossRef]

52. Amorim, C.; Souza, R.; Araújo, A.; Montenegro, M.; Silva, V. SI lab-on-valve analysis of histamine using potentiometric detection for food quality control. Food Chem. 2010, 122, 871-876. [CrossRef]

53. Tóth, K.; Stulík, K.; Kutner, W.; Fehér, Z.; Lindner, E. Electrochemical detection in liquid flow analytical techniques: Characterization and classification (IUPAC Technical Report). Pure Appl. Chem. 2004, 76, 1119-1138. [CrossRef]

54. Montenegro, M.C.B.S.M.; Araújo, A.N. Flow Potentiometry. In Advances in Flow Analysis; Trojanowicz, M., Ed.; Wiley-VCH: Weinheim, Germany, 2008.

55. Amorim, C.G.; Araújo, A.N.; Montenegro, M.C.B.S.M.; Silva, V.L. Sequential Injection Lab-on-Valve Procedure for the Determination of Amantadine Using Potentiometric Methods. Electroanalysis 2007, 19, 2227-2233. [CrossRef]

56. Ahammad, A.J.S.; Lee, J.-J.; Rahman, A. Electrochemical Sensors Based on Carbon Nanotubes. Sensors 2009, 9, 2289-2319. [CrossRef] [PubMed]

57. Yuan, D.; Anthis, A.H.C.; Ghahraman Afshar, M.; Pankratova, N.; Cuartero, M.; Crespo, G.A.; Bakker, E. All-Solid-State Potentiometric Sensors with a Multiwalled Carbon Nanotube Inner Transducing Layer for Anion Detection in Environmental Samples. Anal. Chem. 2015, 87, 8640-8645. [CrossRef] [PubMed]

58. Crespo, G.A.; Macho, S.; Rius, F.X. Ion-Selective Electrodes Using Carbon Nanotubes as Ion-to-Electron Transducers. Anal. Chem. 2008, 80, 1316-1322. [CrossRef] [PubMed]

59. Desimoni, E.; Brunetti, B. About Estimating the Limit of Detection by the Signal to Noise Approach. Pharm. Anal. Acta 2015, 6, 4. [CrossRef]

60. Daems, D.; De Wael, K.; Vissenberg, K.; Van Camp, G.; Nagels, L. Potentiometric sensors doped with biomolecules as a new approach to small molecule/biomolecule binding kinetics analysis. Biosens. Bioelectron. 2014, 54, 515-520. [CrossRef]

61. ICH. ICH Harmonized Tripartite Guideline: Validation of Analytical Procedures: Text and Methodology Q2 (R1); ICH: Geneva, Switzerland, 2005.

62. Eurpean Commission. Commission Decision of 12 August 2002 implementing Council Directive 96/23/EC concerning the performance of analytical methods and the interpretation of results. Off. J. Eur. Communities 2002, 221, 8-36.

63. Sekula, J.; Everaert, J.; Bohets, H.; Vissers, B.; Pietraszkiewicz, M.; Pietraszkiewicz, O.; Du Prez, F.; Vanhoutte, K.; Prus, P.; Nagels, L.J. Coated Wire Potentiometric Detection for Capillary Electrophoresis Studied Using Organic Amines, Drugs, and Biogenic Amines. Anal. Chem. 2006, 78, 3772-3779. [CrossRef]

64. Rossi, R.; Saluti, G.; Moretti, S.; Diamanti, I.; Giusepponi, D.; Galarini, R. Multiclass methods for the analysis of antibiotic residues in milk by liquid chromatography coupled to mass spectrometry: A review. Food Addit. Contam. Part A 2017, 35, $241-257$. [CrossRef]

65. Vuran, B.; Ulusoy, H.I.; Sarp, G.; Yilmaz, E.; Morgül, U.; Kabir, A.; Tartaglia, A.; Locatelli, M.; Soylak, M. Determination of chloramphenicol and tetracycline residues in milk samples by means of nanofiber coated magnetic particles prior to highperformance liquid chromatography-diode array detection. Talanta 2021, 230, 122307. [CrossRef]

66. Tang, H.-Z.; Wang, Y.-H.; Li, S.; Wu, J.; Gao, Z.-X.; Zhou, H.-Y. Development and application of magnetic solid phase extraction in tandem with liquid-liquid extraction method for determination of four tetracyclines by HPLC with UV detection. J. Food Sci. Technol. 2020, 57, 2884-2893. [CrossRef] [PubMed]

67. Yue, Z.; Qiu, Y.; Liu, X.; Ji, C. Determination of Multi-Residues of Tetracyclines and Their Metabolites in Milk by High Performance Liquid Chromatography-Tandem Positive-ion Electrospray Ionization Mass Spectrometry. Chin. J. Anal. Chem. 2006, 34, 1255-1259. [CrossRef]

68. Mamani, M.C.V.; Reyes, F.; Rath, S. Multiresidue determination of tetracyclines, sulphonamides and chloramphenicol in bovine milk using HPLC-DAD. Food Chem. 2009, 117, 545-552. [CrossRef]

69. Kaynaker, M.; Antep, M.; Merdivan, M. Determination of Tetracyclines in Milk, Eggs and Honey Using in-situ Ionic Liquid Based Dispersive Liquid-Liquid Microextraction. J. Anal. Chem. 2018, 73, 23-29. [CrossRef] 
70. Al-Afy, N.; Sereshti, H.; Hijazi, A.; Nodeh, H.R. Determination of three tetracyclines in bovine milk using magnetic solid phase extraction in tandem with dispersive liquid-liquid microextraction coupled with HPLC. J. Chromatogr. B 2018, 1092, 480-488. [CrossRef] [PubMed]

71. Wang, S.; Zhang, J.; Li, C.; Chen, L. Analysis of tetracyclines from milk powder by molecularly imprinted solid-phase dispersion based on a metal-organic framework followed by ultra high performance liquid chromatography with tandem mass spectrometry. J. Sep. Sci. 2018, 41, 2604-2612. [CrossRef]

72. de Faria, H.; Rosa, M.A.; Silveira, A.T.; Figueiredo, E.C. Direct extraction of tetracyclines from bovine milk using restricted access carbon nanotubes in a column switching liquid chromatography system. Food Chem. 2017, 225, 98-106. [CrossRef] 